\title{
Projected Urbanization Impacts on Surface Climate and Energy Budgets in the Pearl River Delta of China
}

\author{
Chunhong Zhao, ${ }^{1,2,3}$ Qunou Jiang, ${ }^{4}$ Zhongxiao Sun, ${ }^{5}$ Haiyue Zhong, ${ }^{6}$ and Shasha Lu${ }^{7}$ \\ ${ }^{1}$ Institute of Geographic and Natural Resources Research, Chinese Academy of Sciences, Beijing 100101, China \\ ${ }^{2}$ Center for Chinese Agricultural Policy, Chinese Academy of Sciences, Beijing 100101, China \\ ${ }^{3}$ University of Chinese Academy of Sciences, Beijing 100049, China \\ ${ }^{4}$ School of Soil and Water Conservation, Beijing Forestry University, Beijing 100038, China \\ ${ }^{5}$ School of Mathematics and Physics, China University of Geosciences, Wuhan 430074, China \\ ${ }^{6}$ College of Land Management, Huazhong Agricultural University, Wuhan 430070, China \\ ${ }^{7}$ School of Economics and Management, Beijing Forestry University, Beijing 100083, China \\ Correspondence should be addressed to Chunhong Zhao; zhao.chun.hong2007@163.com
}

Received 18 July 2013; Accepted 17 September 2013

Academic Editor: Xiangzheng Deng

Copyright (C) 2013 Chunhong Zhao et al. This is an open access article distributed under the Creative Commons Attribution License, which permits unrestricted use, distribution, and reproduction in any medium, provided the original work is properly cited.

\begin{abstract}
The climate impacts of future urbanization in the Pearl River Delta (PRD) region in China were simulated with the Dynamics of Land Systems (DLS) model and the Weather Research and Forecasting (WRF) model in this study. The land use and land cover data in 2000 and 2020 were simulated with the DLS model based on the regional development planning. Then the spatial and temporal changes of surface air temperature, ground heat flux, and regional precipitation in 2020 were quantified and analyzed through comparing simulation results by WRF. Results show that the built-up land will become the dominant land use type in the PRD in 2020. Besides, the near-surface air temperature shows an increasing trend on the whole region in both summer and winter, but with some seasonal variation. The urban temperature rise is more apparent in summer than it is in winter. In addition, there is some difference between the spatial pattern of precipitation in summer and winter in 2020; the spatial variation of precipitation is a bit greater in summer than it is in winter. Results can provide significant reference for the land use management to alleviate the climate change.
\end{abstract}

\section{Introduction}

Urbanization can lead to massive loss of cultivated land, forestry area, and grassland and pose a threat to national food security and ecological safety [1]. More importantly, it can change the land surface properties and consequently influence the regional climate $[2,3]$. The urban areas have a higher heat-storage capacity, Bowen ratio, and surface roughness in comparison to the rural areas [4]. These differences lead to the change of dynamic processes in the atmospheric boundary layer and the surface energy budget, which ultimately affect the regional climate in and around the urban areas [5].

More attention should be paid to the climate effect of urbanization since more than half of the world's population resides in the urban areas, which is expected to continue to increase [6-8]. The research on the climate impacts of urbanization can help to predict and solve the problems caused by climate change more scientifically and efficiently. For example, Seto and Shepherd [9] indicated that the land use and land cover changes in the urban area exerted great impacts on the climate. Stone Jr. [10] suggested that the climate change could be more efficiently mitigated through regulating the land use change than only controlling the greenhouse gas emission. Besides, Stone et al. [11] recommended that the municipal and state governments should broaden climate action plans to include the urban-scale heat management strategies in addition to imposing greenhouse gas emission controls.

There is still very limited knowledge on the impacts of rapid urbanization on the future regional climate [3]. 
Although it has been easier to detect the regional effect of urbanization with the help of a series of regional climate models, the effects of these actions on future climate are still far from well understood since the anthropogenic impacts on Earth's surface continue to increase [11, 12]. A well-acknowledged phenomenon of the climate effect of urbanization is the urban heat island effect (UHI), which is characterized by the temperature contrast between the city and its surrounding areas [13]. UHI can influence the local circulation patterns, which may further have some effects on the precipitation [14].

It is necessary to implement valid prediction of the changing trend of the future urbanization in order to forecast the climate effects of future urbanization more reasonably. In other words, it is necessary to take into account the proposed framework of the development planning of a specific region. Therefore this study analyzed the potential climate effects of the future land use decisions on the assumption based on the regional development planning. The reasonable prediction of the climate effects of urbanization can provide the basis and guidelines for the land use structure optimization, which is of great significance to the determination of the reasonable city scale.

The remainder of this paper is organized as follows. Section 2 introduces the background of the study area, especially its characteristics of urbanization. Section 3 describes the two main models used in this study, Dynamics of Land Systems (DLS) and Weather Research and Forecasting (WRF) model, and explains the model experiments performed in this study. Section 4 shows the result of the model performance and outlines the effects of the future urbanization on the regional climate projected by the high-resolution simulation. Finally, Section 5 shows the discussion and conclusion.

\section{Study Area}

The Pearl River Delta (PRD), located in the southern part of Guangdong Province in China (111.5-115.5 E, $\left.21.5-25^{\circ} \mathrm{N}\right)$, has been one of the fastest developing regions in the world since the 1980s (Figure 1). There has been phenomenal economic and industrial growth in the PRD since the economic reform at the end of the 1970s in China, and this region has been one of the world's largest manufacturing and industrial bases. It accounts for $30 \%$ of the population of Guangdong Province, but it creates the $77 \%$ of the province's GDP. This region is experiencing rapid urbanization (Figure 2), and there have been many large cities in the region, that is, Hong Kong, Guangzhou, Shenzhen, Dongguan, Zhongshan, Foshan, and Macau. According to the data issued by National Bureau of Statistics of China, proportion of Urban Population to Permanent Population by city of the PRD was $71.59 \%$ in 2000 and $82.72 \%$ in 2010 .

As one of three major economic corridors of China, PRD has received great attention of the urban climatologists. Previous researches show that urbanization in this region contributes to the increase of surface temperature due to the land use change $[15,16]$. Some researches on the urban land change over PRD also found that the urban heat island effect (UHI) increased the air temperature gradient

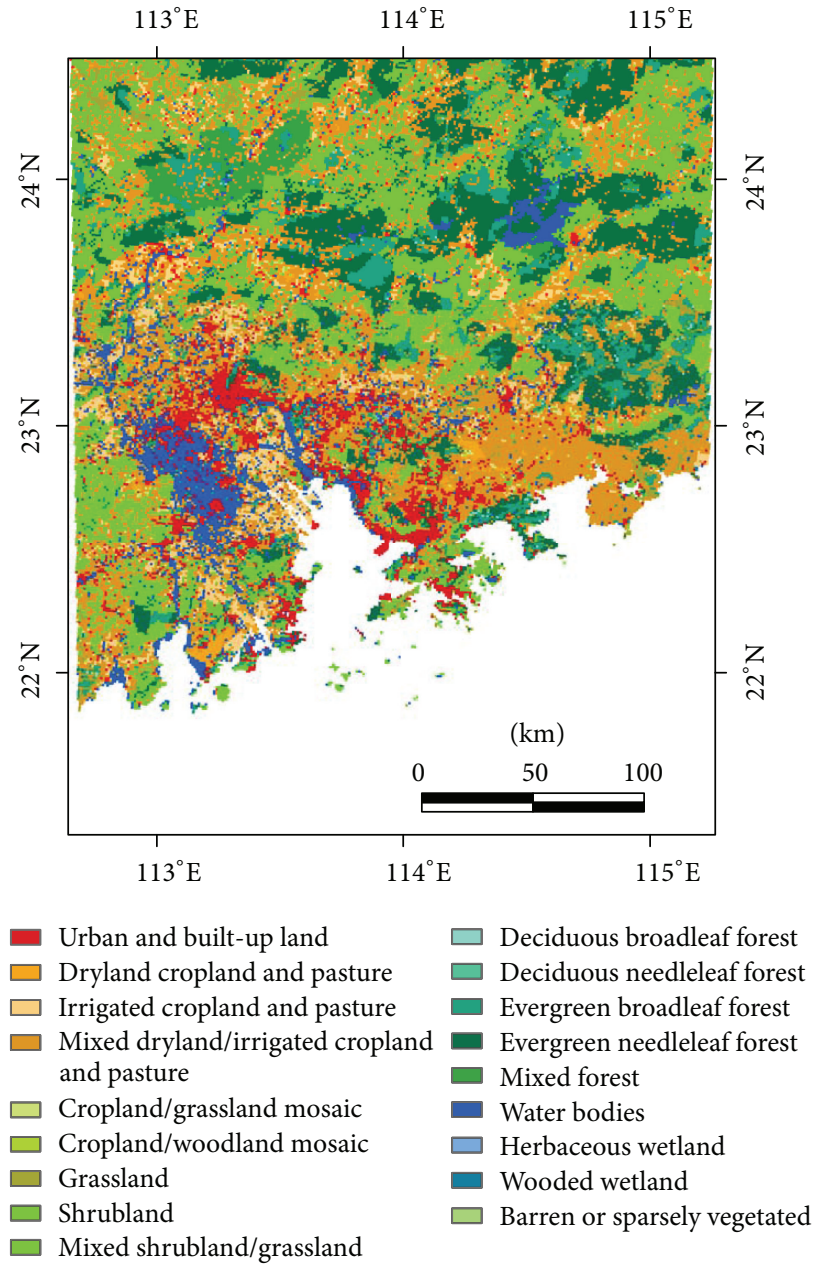

FIGURE 1: Land use/cover types of the USGS classification system in the PRD in year 2000.

between the urban area and the nearby ocean, leading to an enhancement of the land-sea breeze circulation [17]. The PRD experiences more heavy precipitation but less slight precipitation compared to the surrounding nonurban regions [13]. In addition, there is some relationship between the urban land use and the reduced rainfall over the urban area in the dry winter seasons, but not in summer [18]. In other words, there is some seasonal variation in the effects of urbanization on the rainfall over PRD region.

The reasonable and orderly regional development heavily depends on the development planning. The National Development and Reform Commission have issued "Skeleton of the Reform and Development Planning in Pearl River Delta (2008-2020)" on April 4, 2010, which has been implemented very well. Beside, Guangdong Provincial Government has issued "Territorial Planning of Guangdong Province (20062020)" on 18 April 2013, in order to formulate the reasonable planning of expansion of regional built-up land. According to this planning, the built-up land in Guangdong Province will reach 2.0060 million ha in 2020 , which is $10 \%$ more than that in 2010, and the land use intensity in the optimized 


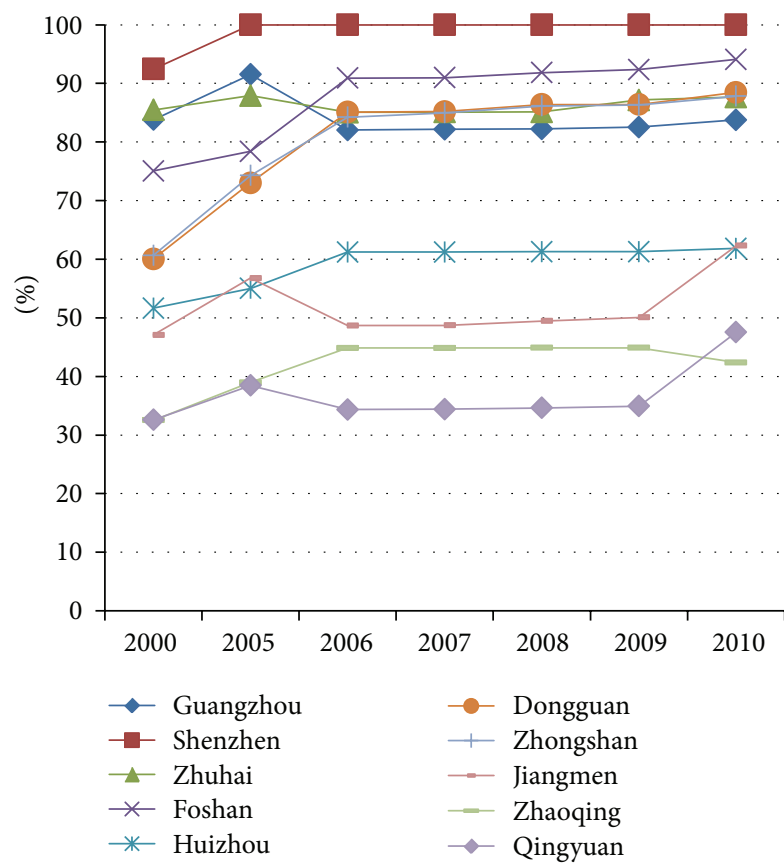

FIGURE 2: Proportion of urban population to permanent population by city of the PRD. Note: the data in 2000 and 2005 in this figure are calculated according to Interim Regulations on Statistical Classification of Urban and Rural Population issued by National Bureau of Statistics in 1999. The 2006 data are calculated according to Provisional Regulations on Statistical Classification of Urban and Rural Population issued by National Bureau of Statistics in 2006.

and improved area of Pearl River Delta will reach $40.52 \%$. Besides, the land use intensity of the optimized development region of Pearl River Delta (fringe area), the coastal key development region at the sides, and Shaoguan-ShanweiYangjiang moderate development region will reach $12.94 \%$, $19.12 \%$ and $10.59 \%$, respectively, which will lead to wellbedded gradients of the land use intensity.

The pace of urban expansion, which is one of the major indicators of the urbanization, will continue to increase in the study area, and therefore this region is an ideal area to analyze the urbanization and its climate effects in China. In this study, the future urbanization in the PRD was first predicted according to the regional development planning, and subsequently the regional climate effect of the urbanization was further analyzed, which is of great importance to the research on the influence of urbanization on the climate. In order to give full consideration to the integrity of regional development, this study has simulated the change of urban land in the whole Guangdong Province with the DLS model. Given the potential changes in the area and land use intensity of built-up land in the PRD, we initiated a study to investigate the potential impacts of the implementation of "Territorial Planning of Guangdong Province (2006-2020)" strategy on local climate through examining the surface energy balance across a range of urban residential densities.

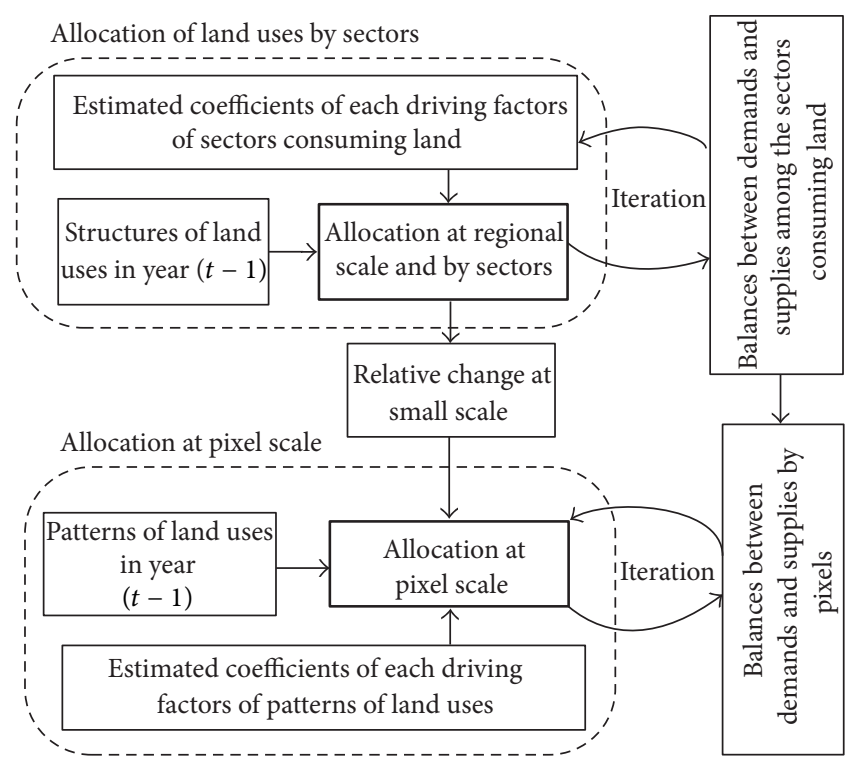

FIGURE 3: Space spatial distribution pattern of various land use types under the regional planning.

\section{Data and Methodology}

3.1. Dynamic Simulation of City Expansion. To predict the future urbanization, the Dynamics of Land System (DLS) model was used in this study, which is capable of solving the problems existing in the currently available methods and of integrating multiple data sources to simulate the dynamics of land systems [19]. There are two special features in the DLS model. On the one hand, it reaches a balance by incorporating a dual-level strategy: a scenario analysis of land demand at a regional level and a spatial desegregation of land uses at a detailed pixel level. On the other hand, it takes into account the interaction among influencing factors of land use and the interaction between neighbor pixels for these influencing factors.

There are four major modules in the DLS model, including scenario analysis module, spatial analysis module, the conversion rules module, and spatial analysis module. In this study, scenario analysis module is used to express urban land change as well as other land types need under regional planning. Spatial analysis module is used to calculate the probability values of various land use types in each grid unit through spatial regression analysis for driving factors which are emphasized in the next paragraph. Transfer rules module is used to express possibility of a certain type of land transfer to urban land on each grid cell. Space allocation module implements spatial distribution pattern of various land use types especially urban land under regional planning on the grid. Space allocation module takes land uses into account in both sector and pixel scale. In this study, we first allocate area demand of different land types to various industries according to supply-demand situation of different industries on land under the regional planning. Then, we forecast the spatial distribution of land use in the grid scale by supply and demand balance analysis (Figure 3 ). 
TABLE 1: Influencing factors of land uses considered in the DLS model in the case study.

\begin{tabular}{|c|c|c|c|}
\hline Influencing factors & Variables & Unit & Definitions \\
\hline \multirow{3}{*}{ Natural conditions } & DEM & M & Elevation \\
\hline & Slope & Degree & Slope \\
\hline & Splain & $\%$ & Proportion of Plain \\
\hline Traffic variables & RoadDEN & $\mathrm{km} / \mathrm{km}^{2}$ & Density of traffic route \\
\hline \multirow{4}{*}{ Proximity variables } & DpvCap & $\mathrm{km}$ & Distance to province capital \\
\hline & DHYW & $\mathrm{km}$ & Distance to the highway \\
\hline & D2provw & $\mathrm{km}$ & Distance to the province way \\
\hline & D2port & $\mathrm{km}$ & Distance to the port \\
\hline \multirow{9}{*}{ Socioeconomic variables } & NonAgr & & Nonagricultural labor force \\
\hline & ArgProp & $\%$ & Proportion of agricultural population in the later period \\
\hline & POP1 & Person & Total population in the later period \\
\hline & GDP1 & Hundred million Yuan & GDP by primary industry \\
\hline & GDP2 & Ten thousand Yuan & GDP by secondary industry \\
\hline & GDP3 & Ten thousand Yuan & GDP by tertiary industry \\
\hline & FDI & Ten thousand Yuan & Foreign investment \\
\hline & TranInvest & Ten thousand Yuan & The number of transportation and telecommunications investment zones \\
\hline & DevelopZone & & The number of development zones \\
\hline
\end{tabular}

Note: (1) variables in the later period is represented by the average values over the past 3 years; (2) the price for GDP in the Socio-economic variable is calculated according to the price in year 2000 .

TABLE 2: Major control indicators of land use in Guangdong Province.

\begin{tabular}{lcccc}
\hline Index & 2005 & 2010 & 2020 & Index property \\
\hline Inventory of cultivated land & 295.27 & 291.40 & 290.87 & Obligatory \\
Area of basic farmland & 284.67 & 255.60 & 255.60 & Obligatory \\
Area of garden-plot & 92.48 & 88.86 & 93.08 & Prospective \\
Area of forests & 1015.74 & 1024.68 & 1026.16 & Prospective \\
Area of grasslands & 2.76 & 2.77 & 2.74 & Prospective \\
Total area of built-up land & 171.53 & 182.61 & 200.60 & Prospective \\
Area of urban and rural built-up land & 131.88 & 140.00 & 152.30 & Prospective \\
Area of land for mining and industry & 66.58 & 75.00 & 91.30 & Prospective \\
Area of land for transportation, water conservancy and other purposes & 39.65 & 42.61 & 48.3 & Prospective \\
Area of land for mining and industry per capital (m ${ }^{2} /$ person) & 119 & 118 & 118 & Obligatory \\
\hline
\end{tabular}

Note: the data is from territorial planning of Guangdong Province (2006-2020) and the data is measured by ten thousand ha.

The dynamics of a land system are actually influenced by a couple of factors. In this study, the influencing factors can generically be categorized into four kinds: geophysical, climatic, proximity, and socioeconomic variables (Table 1). In this study, the scenario of land use in 2020 was derived by an interpolation process based on a reference condition in "Territorial Planning of Guangdong Province (2006-2020)" from the Government of Guangdong Province and "Reform and Development Plan of the Pearl River Delta Region (2008-2020)" from the national development and Reform Commission.

The overall objective in this region is mainly to protect the farmland in order to guarantee the total area of the basic cultivated land, adjust the structure and layout of land use, and implement the optimal and intensive land use. The two plans regulated the main indictors of land use (Table 2).
The urbanization level in Guangdong Province will reach $71 \%-73 \%$ by 2020 . Besides, the population in Guangdong Province will increase from one hundred and ten million to one hundred and twenty million by 2020 , among which the population in the PRD will account for $45 \%-50 \%$ of the provincial total population, and about 80 million people will live in the cities and towns.

The targets of the adjustment of the land use structure and layout and optimal and intensive land use are as follows: raising the proportion of the land for mining and industry in the built-up land; promoting regional coordinated development and making the proportion of the newly increased built-up land in the plain region of PRD in the total newly increased built-up land decrease from $74.1 \%$ during $1996-2005$ to $47.46 \%$ during $2006-2020$ so as to promote the industrial upgrading and transfer in the PRD; 


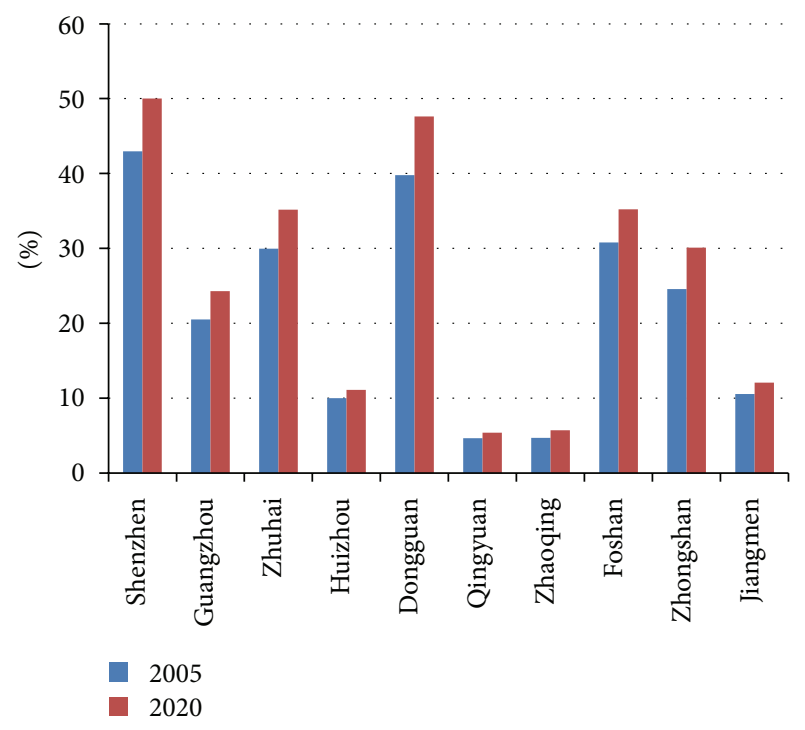

FIGURE 4: Proportion of built-up land in the total land area in major cities.

strictly controlling the unordered expansion of the land for mining and industry, and making the area of land for mining and industry per capital during the planning period decrease from $119 \mathrm{~m}^{2} /$ person in 2005 to $118 \mathrm{~m}^{2} /$ person in 2020; making the total built-up land area show significant regional heterogeneity (Figure 4 ).

3.2. Numerical Simulation Model. WRF is a next-generation, limited-area, nonhydrostatic, and mesoscale modeling system with a terrain-following eta coordinate [20]. The newest version of WRF has been coupled with the Noah land surface and UCM. The UCM is a single-layer model used to parameterize the effects of urban canopy geometry on the surface energy balance and low level wind shear [21]. It estimates both the surface temperature and heat flux from three surface types: roof, wall, and road, and accurately reproduces the characteristics of the diurnal range and nocturnal cooling rates on surface air temperature [22]. Many studies have verified that the WRF model coupled with the simple urban canopy model has good ability to capture urban heat islands, boundary layer structures, and urban plume for several metropolitan areas [23-25].

A Lambert conformal conic projection is used for the model's horizontal coordinates. The main physical parameterizations used include the new version of rapid radiative transfer model (RRTMG) [26], the WRF single-moment three-class scheme microphysical parameterization (WSM3) [27], the new Kain-Fritsch convective parameterization (K-F) [28], and the Yonsei University (YSU) planetary boundary layer (PBL) scheme [29].

\section{Result}

4.1. Urban Expansion by 2020. The simulation result of the urban expansion indicated that the built-up area will
TABLE 3: Schemes of the simulation experiment.

\begin{tabular}{lcc}
\hline Experiment & Simulation period & $\begin{array}{c}\text { Land cover data used in the } \\
\text { WRF model }\end{array}$ \\
\hline case CURURB & $2001.01-2010.12$ & Land cover data of 2000 \\
case FUTURB & $2010.01-2020.12$ & Land cover data of 2020 \\
\hline
\end{tabular}

continually expand as the time goes by, but the pace of expansion will gradually slow down (Figure 5). The regional heterogeneity of the built-up land expansion indicated that the newly increased built-up land will mainly concentrate in the regions where the urbanization level is relatively high, for example, PRD, Zhanjiang, and Chaoshan. The built-up land will have been approximately the dominant land use type in the PRD by 2020. There is also some increase of urban land in other regions, but the increment is relatively small. This suggests that the large cities have a better economic foundation and can attract more foreign investment and labor force, which can further accelerate the development of these cities.

4.2. Experiment Design. The main objective of this study is to explore the effects of the future urban expansion on regional climate, and two experiments with different land cover data were used to evaluate the impacts of future urbanization. The sensitivity experiment (case FUTURB) represents the future urban expansion, and the land cover data for the FUTURB were updated with the output of the DLS model. The control experiments (case CURURB) represent the current land cover conditions, with the land cover data updated with the data extracted from the MODIS satellite observations in 2000. The experiments were designed and run for the entire year in order to determine the impacts of future urbanization on the regional climate in different seasons and months. The two experiments were carried out in both the summer (June to August, JJA) and winter (December to February, DJF) in order to determine the impacts of future urbanization on the regional climate in different seasons. Besides, the first month was considered as the spin-up period so as to minimize the influence of the initial conditions. Finally, the simulation results were integrated for 20 years from January 1 2001, to December 31, 2020 (Table 3), and the differences in simulation results between FUTURB and CURURB were used to analyze the impacts of urbanization on the climate.

4.3. Model Validation. The ability of the WRF model to simulate the climate change in the study area was validated through comparing the simulation results of the case CURURB in 2005 with the observation data from the national standard meteorological observation dataset provided by China meteorological administration (http://www.cma.gov .cn/2011qxfw/2011qsjcx/). Table 4 shows the comparison between simulated and observed annual average temperature and precipitation. The errors between the simulations and observations of mean of $2 \mathrm{~m}$ temperature $\left(T_{2 \mathrm{~m}}\right)$ are less than $1.0^{\circ} \mathrm{C}$ in the study area except a few stations. The simulation results of the average monthly precipitation agree with the observations very well, with the relative errors less than $10 \%$. 


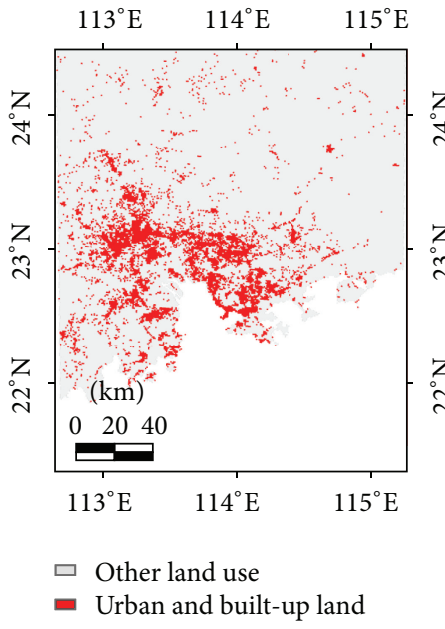

(a)

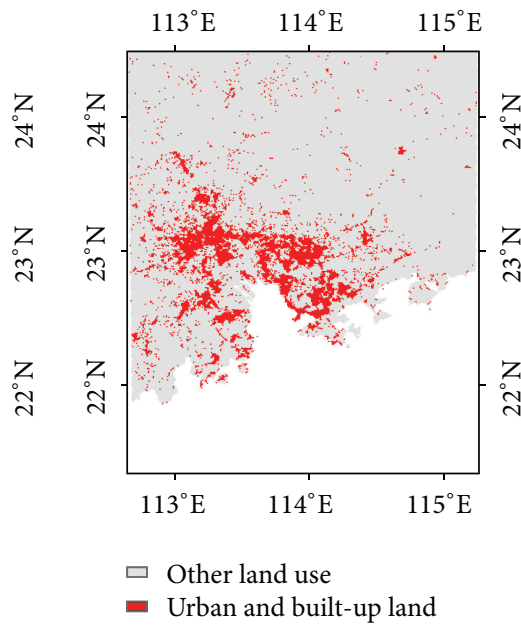

(b)

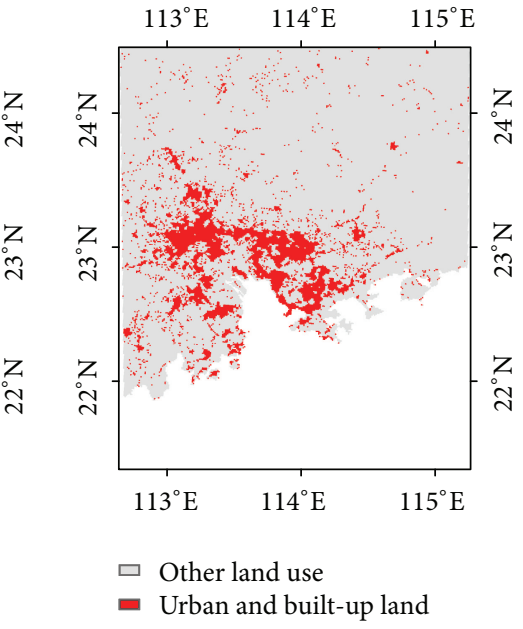

(c)

FiguRE 5: The simulation result of the urban expansion under the regional planning: (a) 2010, (b) 2015 and (c) 2020.

TABLE 4: Comparison of nine urban meteorological stations observed (OBS) and model simulated (SIM) mean air temperature ( $T_{2 \mathrm{~m}}$, degree Celsius) and precipitation ( $P$, millimeters) of the year 2005 over the 16 observation sites.

\begin{tabular}{|c|c|c|c|c|c|c|}
\hline \multirow{2}{*}{ Site name } & \multicolumn{3}{|c|}{$T_{2 \mathrm{~m}}$} & \multicolumn{3}{|c|}{ Precipitation } \\
\hline & SIM & OBS & Error & SIM & OBS & Error \\
\hline Lianxian & 20.05 & 19.08 & 0.97 & 1636.0 & 1560.7 & 75.3 \\
\hline Shaoguan & 20.50 & 21.64 & -1.14 & 1772.2 & 1669.4 & 102.8 \\
\hline Fogang & 21.42 & 19.74 & 1.68 & 1937.2 & 1780.3 & 156.9 \\
\hline Lianping & 20.38 & 18.56 & 1.82 & 1834.3 & 1665.5 & 168.8 \\
\hline Guangning & 21.43 & 21.92 & -0.49 & 2013.4 & 2063.7 & -50.3 \\
\hline Gaoyao & 22.53 & 21.48 & 1.05 & 1905.2 & 1825.2 & 80.0 \\
\hline Guangzhou & 22.78 & 22.5 & 0.27 & 1986.2 & 2012.0 & -25.8 \\
\hline Dongyuan & 22.17 & 21.7 & 0.47 & 2044.4 & 2005.6 & 38.8 \\
\hline Zengcheng & 22.14 & 21.38 & 0.76 & 2278.3 & 2205.4 & 72.9 \\
\hline Huiyang & 22.38 & 21.37 & 1.01 & 1709.2 & 1630.6 & 78.6 \\
\hline Luoding & 22.98 & 21.76 & 1.22 & 1156.5 & 1092.9 & 63.6 \\
\hline Taishan & 22.46 & 23.06 & -0.60 & 1776.1 & 1724.6 & 51.5 \\
\hline Shenzhen & 23.23 & 21.77 & 1.46 & 2143.6 & 2002.1 & 141.5 \\
\hline Shanwei & 22.40 & 21.84 & 0.56 & 2093.3 & 2151.9 & -58.6 \\
\hline Yangjiang & 22.26 & 21.26 & 1.00 & 1644.9 & 1565.9 & 79.0 \\
\hline Shangchuandao & 22.88 & 22.1 & 0.77 & 2608.8 & 2522.7 & 86.1 \\
\hline
\end{tabular}

The simulated temperatures presented a positive bias in all the observation sites except Shaoguan, Guangning, and Taishan. Overall, the WRF model simulates the seasonal variation of temperature in the PRD quite well. However, compared to the observation data, the simulated temperature has roughly a small positive bias and the precipitation is overestimated in some months. Besides the intrinsic limitations of the WRF model, the simulation errors are possibly related to the lack of parameterization of anthropogenic heat release, aerosol influence, and the ideal and uniform urban parameters [30]. Although there are some errors in the simulation result, the bias between simulated and observed results is still acceptable since this study focuses on the difference between two experiments.
4.4. Urbanization Effects on Surface Temperature and Energy Budget. The simulation results indicate that $T_{2 \mathrm{~m}}$ will show an increasing trend on the whole in both the summer and winter, with some seasonal variation (Figure 6). Compared to the result in case CURURB, the summer temperature increment over the whole simulation domain is about $0.012^{\circ} \mathrm{C}$ on average in case FUTURB. The urban temperature will increase more obviously in the summer (by $0.014^{\circ} \mathrm{C}$ on average) than in the winter (by $0.010^{\circ} \mathrm{C}$ on average), which is consistent with the result of previous researches. For example, Cheng and Chan found that spatial and temporal features of the effects of urbanization on the temperature and precipitation are different between summer and winter since the 1980s [31]. It can be found that the warming trend is consistent with 


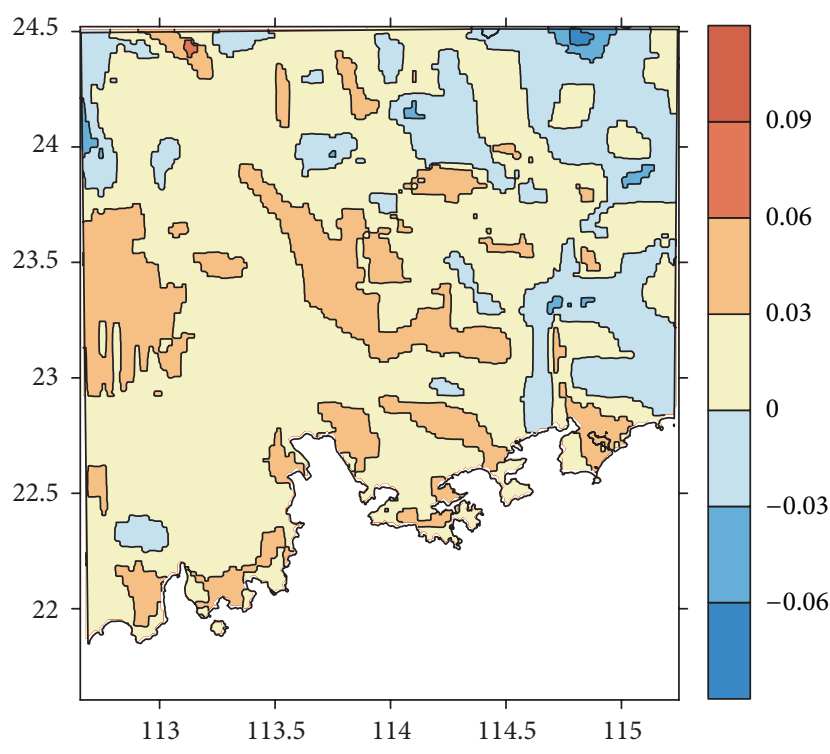

(a)

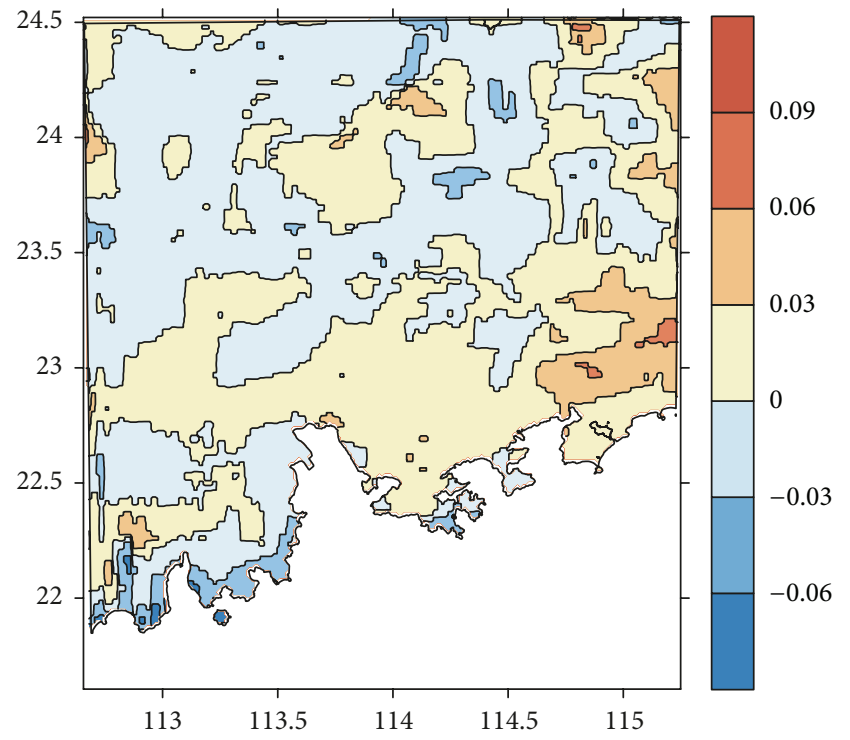

(b)

FIGURE 6: Spatial patterns of the change of $T_{2 \mathrm{~m}}$ in JJA and DJF from the year 2000 to the year 2020. The unit for temperature is degrees Celsius. (a) JJA; (b) DJF.

previous researches even though the temperature increment is lower than that in the historical period. One reason is that this study involved the whole Pearl River Delta rather than the urban area. Another reason is that the urbanization rate of the PRD is lower in the next decade than it was in the past 30 years.

The spatial pattern of seasonal temperature indicates that there is more significant spatial heterogeneity of the impacts of land surface on the temperature change in the winter than in the summer (Figure 6). Overall, the temperature rise due to urbanization shows some obvious spatial heterogeneity in the summer, while it shows no obvious spatial heterogeneity in the winter. Besides, the temperature rise is more obvious in the inland of the PRD than it is in the coastal area in the winter (Figure 6). This tendency is consistent with the simulation result of the urban expansion under the regional planning shown in Figure 5 since the inland of the PRD will experience more rapid urbanization by 2020 . The higher the urbanization level is, the more obviously the temperature increases, especially in the summer. In addition, the urbanization may exert influence on $T_{2 \mathrm{~m}}$ in the summer in two ways. First, there will be no obvious urban expansion in the coastal regions where the cities have covered the whole regions and the afforestation may be even better, while the urban expansion will mainly occur in the regions close to the inland. Second, the specific heat of sea water exerts less influence on the inland than on the coastal regions. The result agrees with the conclusion of previous studies that the temperature increases over the PRD region as well as the Yangtze River Delta, which is also a subtropical climate region located in southeast China, owing to urbanization in the history $[31,32]$.

The surface energy balance plays a key role in influencing the dynamics and thermodynamics above the land surface, and the changes of surface energy balance provide an explicit explanation of the climate effects of urbanization [33]. The simulation results indicate that the urbanization effects on the surface variables are consistent in both the summer and winter. The simulation results show that the sensible heat flux increases while the latent heat flux decreases slightly in the whole year of 2020. The changes in the sensible heat and latent heat mainly result from the increased shortwave absorption and reduced long wave emission in the urban area. In addition, the ground heat flux shows a slightly increasing trend and without significant season variation (Figure 7). The stronger influence on the thermodynamic field in the summer is mainly caused by the greater modification of surface radiation parameters of the urban land use.

The ground heat flux will increase on the whole over the whole simulation domain in both summer and winter compared to that in 2000 . The underlying surface will convert from irrigated cropland or grassland into waterproof surface which is mostly made up of cement during the urbanization processes. The limited availability of surface water due to the change of land surface property will reduce evaporative cooling in urban areas, which limits the heat released from the surface to the atmosphere and makes the ground heat flux increase accordingly. Besides, the variation of ground heat flux is higher and the variation range is wider in the summer than in the winter (Figure 7(b)). It may be because the incident shortwave radiation, which dominates the energy budget of the land surface, is the highest in the summer.

4.5. Urbanization Effects on Precipitation. Precipitation is a key factor in the global water cycle and a proxy for climate change. Estimation of the effect of urbanization on precipitation becomes increasingly important for both climate change research and for its impact on human lives. On the other 


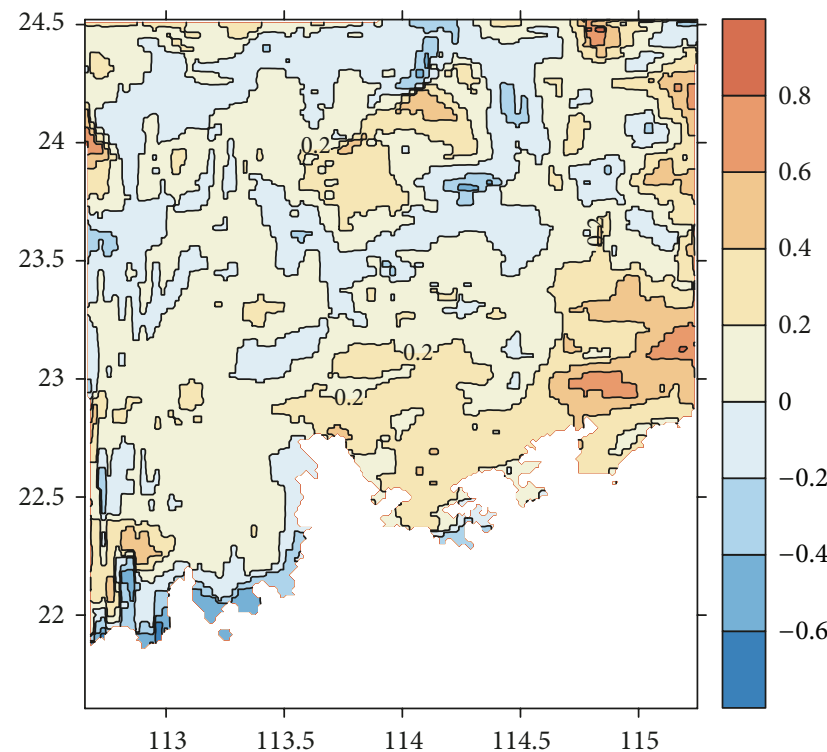

(a)

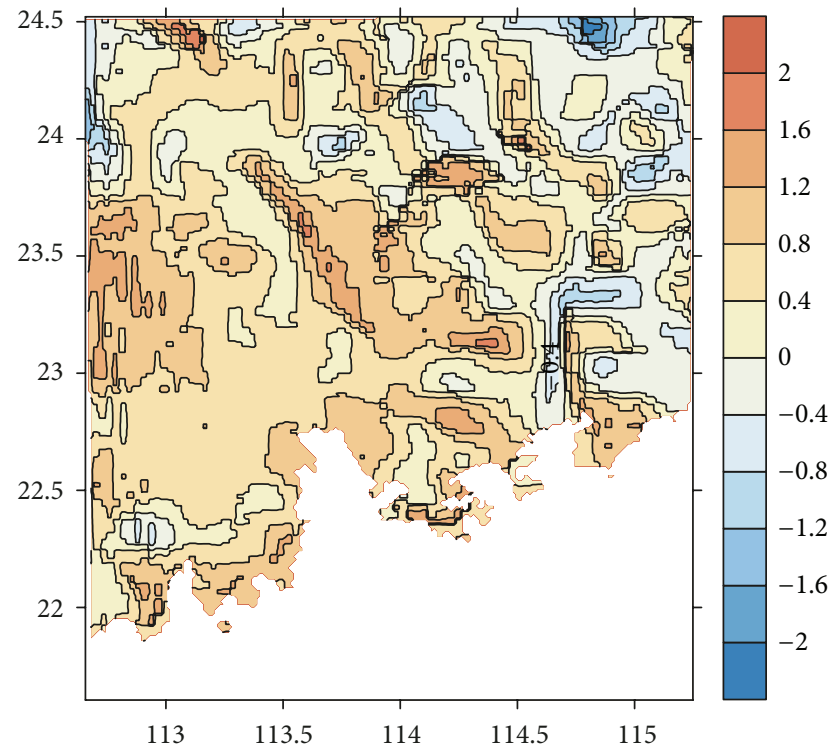

(b)

FIGURE 7: Annual variation of the ground heat flux in JJA and DJF from the year 2000 to the year 2020. The unit is W·m $\mathrm{m}^{-2}$. (a) JJA; (b) DJF.

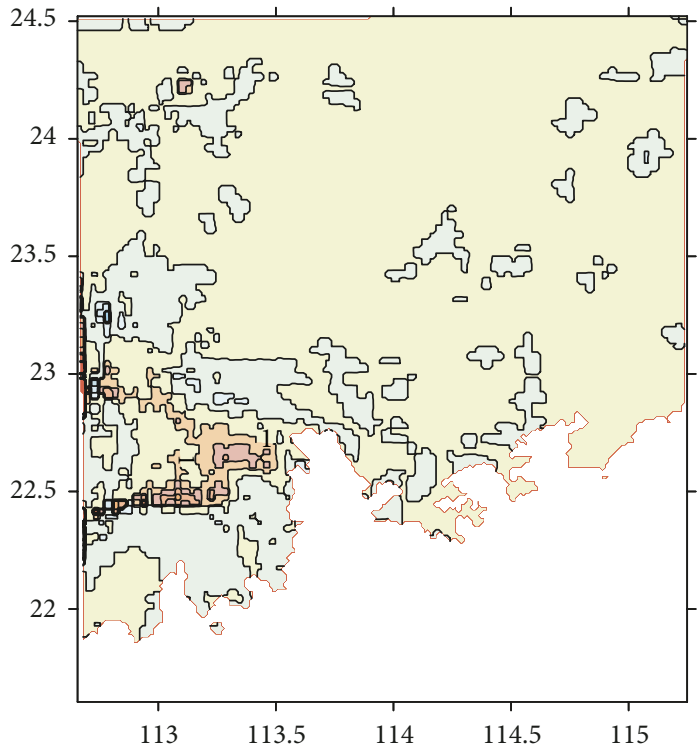

(a)
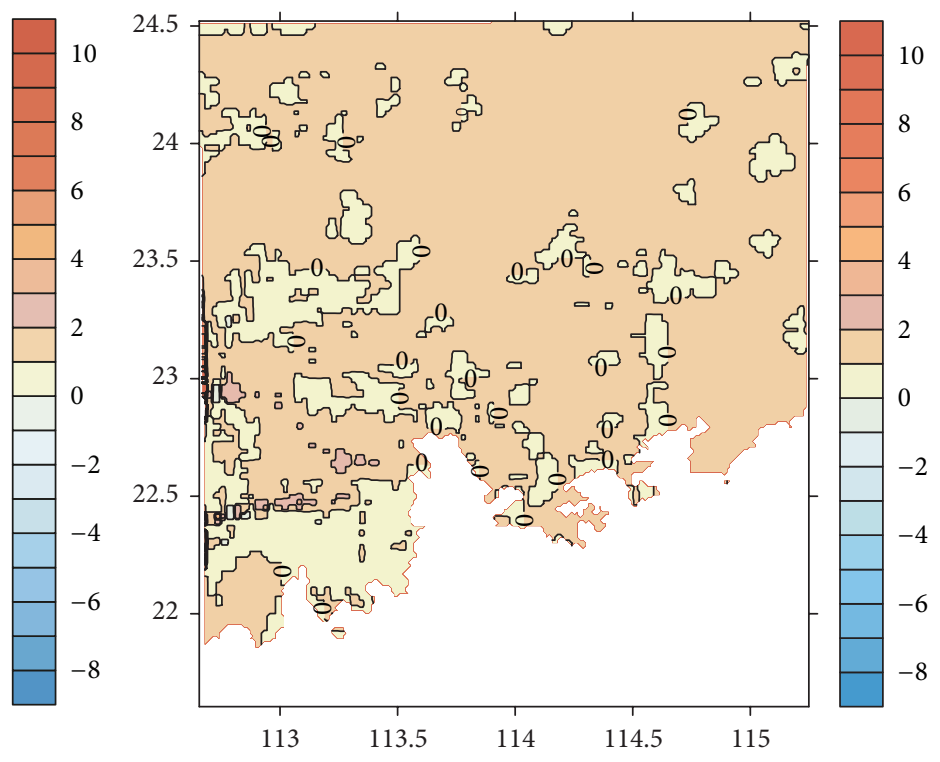

(b)

FIGURE 8: Spatial patterns of the change of precipitation in JJA and DJF from the year 2000 to the year 2020. The unit for precipitation is mm. (a) JJA; (b) DJF.

hand, local forcing as well as synoptic forcing has complicated effects on rainfall, which can enhance the uncertainties of future rainfall prediction.

There is some difference between the spatial patterns of precipitation in the summer and winter of 2020; the spatial variation of precipitation is slightly greater in the summer than that in the winter (Figure 8). For example, there will be slight increase of the precipitation in the inland urban area in the summer of 2020, while the precipitation will increase significantly in the western coastal region of the PRD
(Figure 8(a)). However, the spatial pattern of precipitation change is consistent in the entire PRD region in winter in 2020. In other words, there is slight increase of rainfall in both the inland urban area and the coastal area (Figure 8(b)). In the summer, the prevailing wind enhances the moisture level, which plays an important role in increasing the rainfall over the urban area. Particularly, the strong positive moisture advection makes great contribution to the increase of rainfall over the coastal areas in summer. The increased low-level vertical velocity over the urban area increases the convection 
and consequently leads to more rainfall in the urban areas. In addition, the increased convergence and/or cyclonic anomaly due to urban roughness can increase the precipitation in these areas even when there is little change in the water vapor in lower troposphere. There is a similar mechanism that can contribute to the slight increase of rainfall in the entire PRD in the winter.

The mechanism of urbanization impacts on the precipitation can also help to explain the seasonal variation of precipitation. First and foremost, local forcing has an effect on the precipitation, for example, the prevailing south wind brings more moisture from the sea to the urban area in summer, which leads to the increase of rainfall over the coastal area in summer. Besides, urbanization has greater impacts on the surface variables in the summer than in the winter. For example, the results mentioned above show that $T_{2 m}$ has a positive change in urban area in both the summer and winter; the urban area will become a low-pressure area since the land cover change increases the surface temperature in the urban area. The urbanization increases the surface roughness and consequently reduces the wind speed over the urban area, which will lead to convergence and rising motion of air in the urban area. In fact, the simulation results of this study as well as other numerical experiments all indicate that the surface pressure in the urban area has a decreasing tendency due to urbanization and UHI. In addition, the decreased surface pressure and the increased surface roughness in the urbanized areas lead to the higher surface convergence over the urban area, which increases the rising motion in the urbanized areas. What is more, the urban areas apparently have less vegetation, which is closely related to the higher surface sensible heat and plays an important role in enhancing the convective circulation over the PRD.

\section{Discussion and Conclusion}

This study analyzed the impacts of future urbanization on the regional climate in the PRD of China. The main conclusions could be summarized as follows. The pace of urban expansion, which is one of the major indicators of the urbanization, will continue to increase in the PRD. As the urbanization continues, the land surface energy budget in the cities will change, which plays an important role in influencing the urban climate. Besides, there are various factors that influence the regional precipitation, and the complicated effects of the local and regional influencing factors on the precipitation lead to some uncertainties in the rainfall prediction.

The urban areas over the PRD region apparently have less vegetation, which is closely related to the greater surface sensible heat and will enhance the convective circulation. On the other hand, the less vegetation can definitely decrease the surface latent heat flux, which can reduce the amount of moisture available for cloud formation. In addition, further analyses should be conducted so as to reveal the underlying processes associated with the impacts of urbanization on the rainfall in different seasons.

This study has only analyzed the physical impacts of urban expansion, but the urbanization process is a very complicated process influenced by many factors, and it has various influences on the climate. Pollutant release is another important factor that influences the radiation process over urban areas [34]. It is necessary to carry out more studies that utilize a wide range of scenarios of climate change, land use change, and realistic urban parameters to quantify the effects of different factors on regional climate in the future. Additionally, with the increasing available computational resources, the long-term simulation would be an optimal way to assess the large-scale climate effects of urbanization.

\section{Acknowledgments}

This research was financially supported by the National Key Programme for Developing Basic Science of China (Grant no. 2010CB950900). In addition, the authors thank the editor and three anonymous reviewers for their constructive comments, which helped us to improve the paper.

\section{References}

[1] X. Deng, J. Huang, S. Rozelle, and E. Uchida, "Cultivated land conversion and potential agricultural productivity in China," Land Use Policy, vol. 23, no. 4, pp. 372-384, 2006.

[2] C. Deng and C. Wu, "Examining the impacts of urban biophysical compositions on surface urban heat island: a spectral unmixing and thermal mixing approach," Remote Sensing of Environment, vol. 131, pp. 262-274, 2013.

[3] X. Deng, C. Zhao, and H. Yan, "Systematic modeling of impacts of land use and land cover changes on regional climate: a review," Advances in Meteorology, vol. 2013, Article ID 317678, 11 pages, 2013.

[4] S. Peng, S. Piao, P. Ciais et al., "Surface urban heat island across 419 global big cities," Environmental Science \& Technology, vol. 46, no. 2, pp. 696-703, 2012.

[5] B. Stone, J. J. Hess, and H. Frumkin, "Urban form and extreme heat events: are sprawling cities more vulnerable to climate change than compact cities?" Environmental Health Perspectives, vol. 118, no. 10, pp. 1425-1428, 2010.

[6] B. Cohen, "Urbanization in developing countries: current trends, future projections, and key challenges for sustainability," Technology in Society, vol. 28, no. 1-2, pp. 63-80, 2006.

[7] X. Deng, J. Huang, S. Rozelle, and E. Uchida, "Growth, population and industrialization, and urban land expansion of China," Journal of Urban Economics, vol. 63, no. 1, pp. 96-115, 2008.

[8] X. Deng, J. Huang, S. Rozelle, and E. Uchida, "Economic growth and the expansion of urban land in China," Urban Studies, vol. 47, no. 4, pp. 813-843, 2010.

[9] K. C. Seto and J. M. Shepherd, "Global urban land-use trends and climate impacts," Current Opinion in Environmental Sustainability, vol. 1, no. 1, pp. 89-95, 2009.

[10] B. Stone Jr., "Land use as climate change mitigation," Environmental Science \& Technology, vol. 43, no. 24, pp. 9052-9056, 2009.

[11] B. Stone, J. Vargo, and D. Habeeb, "Managing climate change in cities: will climate action plans work?" Landscape and Urban Planning, 2012.

[12] J. J. Feddema, K. W. Oleson, G. B. Bonan et al., "Atmospheric science: the importance of land-cover change in simulating future climates," Science, vol. 310, no. 5754, pp. 1674-1678, 2005. 
[13] W. Li, S. Chen, G. Chen et al., "Urbanization signatures in strong versus weak precipitation over the Pearl River Delta metropolitan regions of China," Environmental Research Letters, vol. 6, Article ID 034020, 2011.

[14] R. A. Pielke, J. Adegoke, A. Beltrán-Przekurat et al., "An overview of regional land-use and land-cover impacts on rainfall," Tellus, Series B, vol. 59, no. 3, pp. 587-601, 2007.

[15] C.-Y. Lam, "On climate changes brought about by urban living," in Designing High-Density Cities for Social and Environmental Sustainability, pp. 55-61, 2010.

[16] J. Chen, Q. Li, J. Niu, and L. Sun, "Regional climate change and local urbanization effects on weather variables in Southeast China," Stochastic Environmental Research and Risk Assessment, vol. 25, no. 4, pp. 555-565, 2011.

[17] J. C. F. Lo, A. K. H. Lau, F. Chen, J. C. H. Fung, and K. K. M. Leung, "Urban modification in a mesoscale model and the effects on the local circulation in the Pearl River Delta Region," Journal of Applied Meteorology and Climatology, vol. 46, no. 4, pp. 457-476, 2007.

[18] R. K. Kaufmann, K. C. Seto, A. Schneider, Z. Liu, L. Zhou, and W. Wang, "Climate response to rapid urban growth: evidence of a human-induced precipitation deficit," Journal of Climate, vol. 20, no. 10, pp. 2299-2306, 2007.

[19] X. Deng, H. Su, and J. Zhan, "Integration of multiple data sources to simulate the dynamics of land systems," Sensors, vol. 8, no. 2, pp. 620-634, 2008.

[20] J. Jin, N. L. Miller, and N. Schlegel, "Sensitivity study of four land surface schemes in the WRF model," Advances in Meteorology, vol. 2010, Article ID 167436, 11 pages, 2010.

[21] H. Kusaka and F. Kimura, "Coupling a single-layer urban canopy model with a simple atmospheric model: Impact on urban heat island simulation for an idealized case," Journal of the Meteorological Society of Japan, vol. 82, no. 1, pp. 67-80, 2004.

[22] H. Kusaka, H. Kondo, Y. Kikegawa, and F. Kimura, "A simple single-layer urban canopy model for atmospheric models: Comparison with multi-layer and slab models," BoundaryLayer Meteorology, vol. 101, no. 3, pp. 329-358, 2001.

[23] M. Wang, X. Yan, J. Liu, and X. Zhang, "The contribution of urbanization to recent extreme heat events and a potential mitigation strategy in the Beijing-Tianjin-Hebei metropolitan area," Theoretical and Applied Climatology, 2013.

[24] X. Z. Zhang, J. H. Dai, and Q. S. Ge, "Variation in vegetation greenness in spring across eastern China during 1982-2006," Journal of Geographical Sciences, vol. 23, no. 1, pp. 45-56.

[25] J. Wang, J. Feng, Z. Yan, Y. Hu, and G. Jia, "Nested highresolution modeling of the impact of urbanization on regional climate in three vast urban agglomerations in China," Journal of Geophysical Research, vol. 117, no. D21, 2012.

[26] M. J. Iacono, J. S. Delamere, E. J. Mlawer, M. W. Shephard, S. A. Clough, and W. D. Collins, "Radiative forcing by long-lived greenhouse gases: Calculations with the AER radiative transfer models," Journal of Geophysical Research D: Atmospheres, vol. 113, no. 13, Article ID D13103, 2008.

[27] S.-Y. Hong, J. Dudhia, and S.-H. Chen, "A revised approach to ice microphysical processes for the bulk parameterization of clouds and precipitation," Monthly Weather Review, vol. 132, no. 1, pp. 103-120, 2004.

[28] J. S. Kain and J. Kain, "The Kain-Fritsch convective parameterization: an update," Journal of Applied Meteorology, vol. 43, no. 1, pp. 170-181, 2004.
[29] Y. Noh, W. G. Cheon, S. Y. Hong, and S. Raasch, "Improvement of the K-profile model for the planetary boundary layer based on large eddy simulation data," Boundary-Layer Meteorology, vol. 107, no. 2, pp. 401-427, 2003.

[30] M. O. Andreae, C. D. Jones, and P. M. Cox, "Strong present-day aerosol cooling implies a hot future," Nature, vol. 435, no. 7046, pp. 1187-1190, 2005.

[31] C. K. Cheng and J. C. Chan, "Impacts of land use changes and synoptic forcing on the seasonal climate over the Pearl River Delta of China," Atmospheric Environment, vol. 60, pp. 25-36, 2012.

[32] N. Zhang, Z. Gao, X. Wang, and Y. Chen, "Modeling the impact of urbanization on the local and regional climate in Yangtze River Delta, China," Theoretical and Applied Climatology, vol. 102, no. 3, pp. 331-342, 2010.

[33] M. Piringer, C. Grimmond, S. Joffre et al., "Investigating the surface energy balance in urban areas-recent advances and future needs," Water, Air and Soil Pollution: Focus, vol. 2, no. 5-6, pp. 1-16, 2002.

[34] S. C. van den Heever and W. R. Cotton, "Urban aerosol impacts on downwind convective storms," Journal of Applied Meteorology and Climatology, vol. 46, no. 6, pp. 828-850, 2007. 

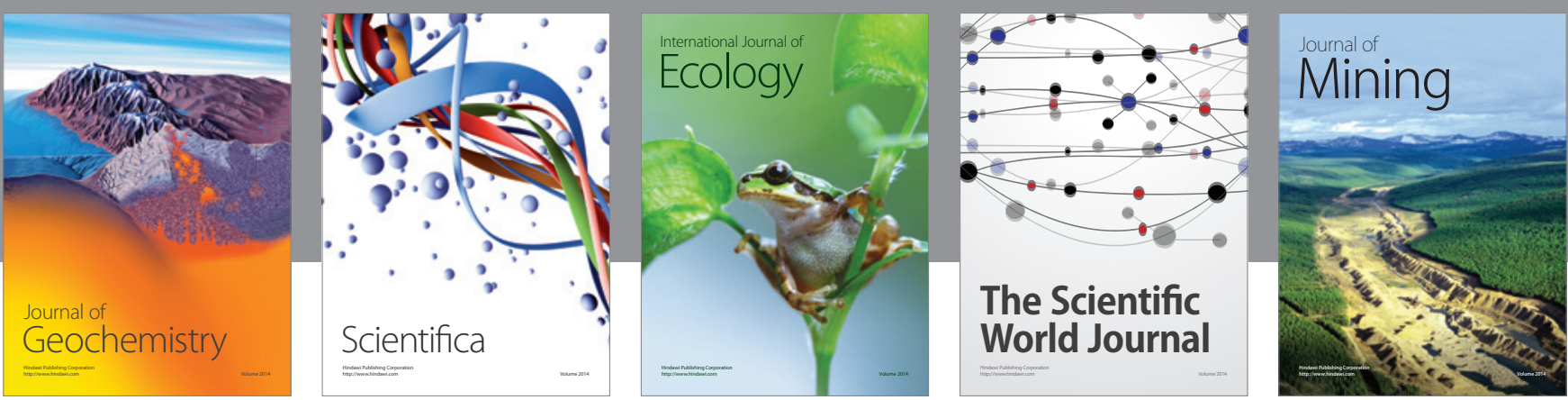

The Scientific World Journal
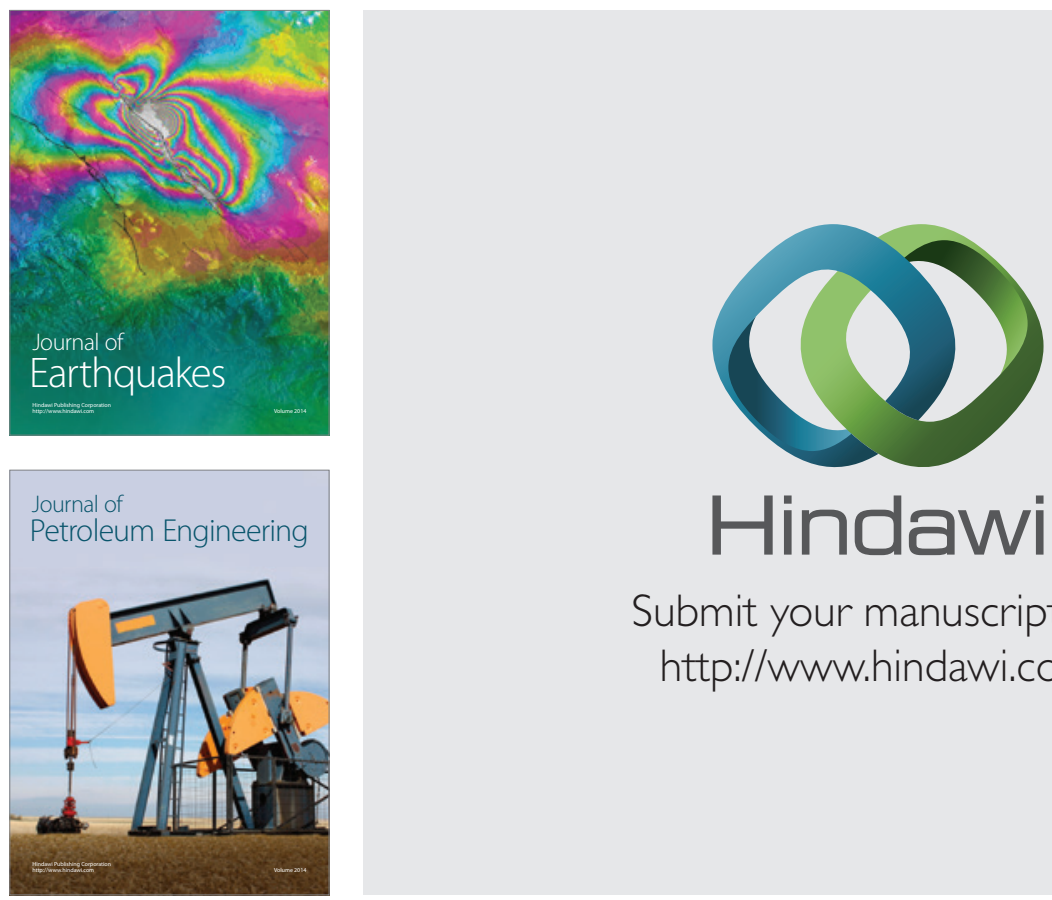

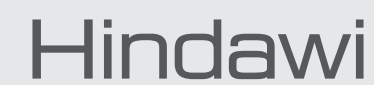

Submit your manuscripts at

http://www.hindawi.com
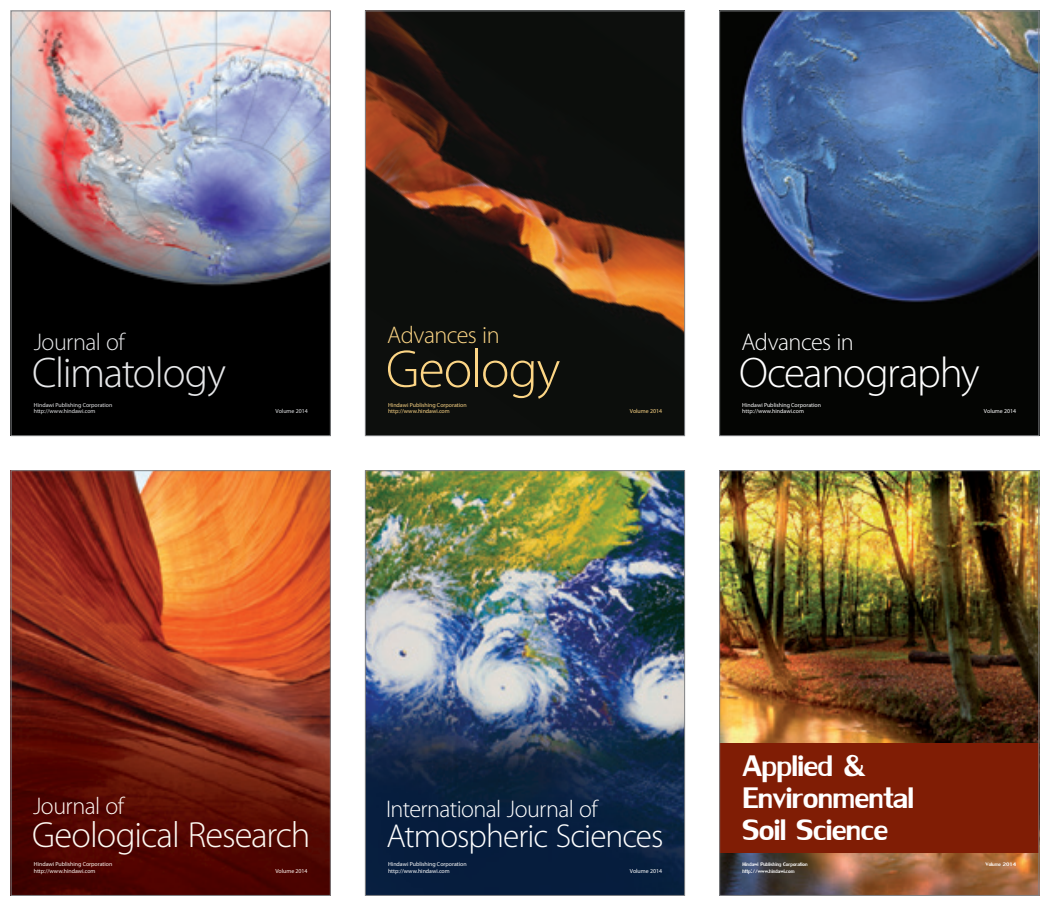
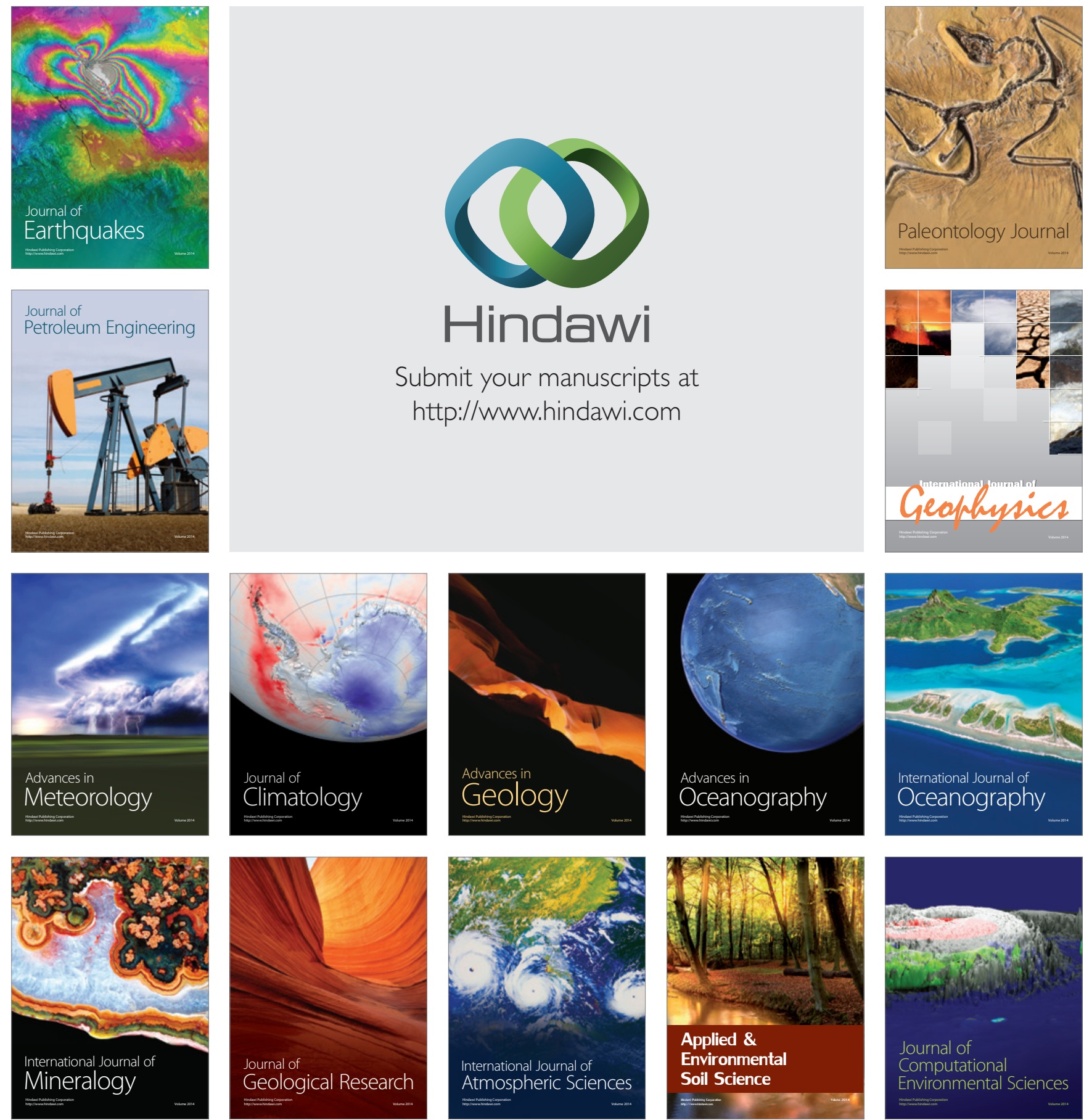